Check for updates

Cite this: RSC Adv., 2018, 8, 35618

Received 19th July 2018

Accepted 11th October 2018

DOI: $10.1039 / c 8 r a 06137 h$

rsc.li/rsc-advances

\section{Imparting sensitivity and selectivity to a gold nanoparticle chemiresistor through thiol monolayer functionalization for sensing acetone}

\author{
Zhenzhen Xie, ${ }^{a}$ Mandapati V. Ramakrishnam Raju, ${ }^{\mathrm{b}}$ Andrew C. Stewart, ${ }^{\mathrm{b}}$ \\ Michael H. Nantz ${ }^{\star b}$ and Xiao-An Fu (iD)*a
}

\begin{abstract}
Chemiresistor-based gas sensors for detection of target volatile organic compounds (VOCs) in air face common challenges of poor sensitivity and selectivity as well as suffering from interference by other constituent gases and/ or humidity. This work demonstrates that functionalizing gold nanoparticles (AuNPs) with a designed thiol monolayer improves sensitivity and selectivity of the derived AuNPs gas sensor. We report the synthesis and application of a thiol ligand fitted with both a urea motif and a tert-butyl end group for functionalizing AuNPs. The AuNPs sensor prepared using the urea thiol ligand demonstrated significantly increased acetone sensing in comparison with tested commercially available thiol-functionalized AuNPs. The sensor worked under ambient temperature and high humidity conditions, and demonstrated a linear relationship between the sensor response and the common logarithm of analyte concentration.
\end{abstract}

\section{Introduction}

The analysis of volatile organic compounds (VOCs), either in air or in exhaled breath, has become a highly active research area, due in large part to increasing air pollution concerns as well as growing interest in using breath analysis for detection of diseases. Acetone is one of the most abundant VOCs in environmental air. Acetone is also an endogenous product of human metabolism for which reported concentration levels in exhaled breath of patients with diabetes were much higher than in the breath of healthy subjects. ${ }^{1}$ As a result, nanostructured metal oxides, $^{2-12}$ carbon nanotubes, ${ }^{13,14}$ polymer nanofibers, ${ }^{15,16}$ and nanoparticles ${ }^{17}$ all have been explored as sensing materials for detection of acetone. ${ }^{18,19}$ However, performance issues, such as low sensitivity, low selectivity, lack of reproducibility, interference of humidity, and sensor aging, continue to plague many of these current sensor materials. Thus, there is a need to develop realtime, portable, and high performance sensors to detect VOCs of interest such as acetone in the range of sub-ppm to ppm.

Chemiresistors based on thiol ligand-functionalized metal nanoparticles are promising for sensing VOCs due to their controllable selectivity, ambient operating temperature, and their ease of integration with other microelectronic systems. ${ }^{20-22}$ Since the first thiol ligand-stabilized gold nanoparticles (AuNPs) chemiresistor for detection of toluene was reported in 1998, ${ }^{23}$ numerous researchers have explored AuNPs-based sensing

${ }^{a}$ Chemical Engineering Department, University of Louisville, Louisville, Kentucky 40292, USA. E-mail: xiaoan.fu@louisville.edu

${ }^{b}$ Department of Chemistry, University of Louisville, Louisville, Kentucky 40292, USA. E-mail: Michael.nantz@louisville.edu platforms to detect VOCs ${ }^{24-32}$ under various conditions, including high humidity. ${ }^{33}$ However, the development of a thiolfunctionalized AuNPs sensor that responds with high sensitivity and selectively to acetone still remains a challenge.

Devising a functional ligand-based chemiresistor to impart high sensitivity and selectivity for sensing target VOCs requires molecular-level control. ${ }^{34}$ The high level of control afforded by $\mathrm{H}$ bonded ensembles in numerous supramolecular structures has inspired us to harness H-bonding to develop a functional sensing device. ${ }^{35,36}$ The seminal report by Kaftory et al. ${ }^{37}$ on the role of electronic interactions between acetone and urea derivatives in determining the crystal structures of adducts has prompted much effort toward developing urea motifs as receptors for the carbonyl functional group. We thus set out to couple the carbonyl selection properties of urea H-bonded networks with the conductive properties of AuNPs to develop a carbonyl-selective sensor.

We previously disclosed the prototype ligand 1-(tert-butyl)-3((11-mercapto-undecyl)oxy)urea for preparing a AuNPs-based sensor array to detect VOCs in air. ${ }^{38}$ The current work reports details of the synthesis of this unprecedented thiol-terminated monoalkoxyurea motif through acylation of an aminooxy intermediate and its incorporation onto AuNPs for detecting trace acetone and other VOCs in air. A VOC-sensing comparison study testing the urea thiol ligand and three commercially available thiols is also presented.

\section{Material and methods}

\section{Material}

Commercial thiols 1 -dodecanethiol, 4-methoxy- $\alpha$-toluenethiol, and 11-mercaptoundecanoic acid as well as hydrogen 
tetrachloroaurate $\left(\mathrm{HAuCl}_{4}\right)$, tetraoctylammonium bromide (TOAB), and Tedlar bags were purchased from Sigma-Aldrich in USA. Sodium borohydride was purchased from Fluka in USA. Deionized water was used for all experimentation. Reagent grade solvents including acetone, ethanol, benzene, and tetrahydrofuran (THF) were used for extractions and for purifications via flash column chromatography. THF was dried by distillation over $\mathrm{Na}$ /benzophenone. Dichloromethane (DCM) and dimethylformamide (DMF) were dried by distillation over $\mathrm{CaH}_{2}$.

Nuclear magnetic resonance (NMR) spectra were obtained using a Varian/Agilent $400 \mathrm{MHz}$ NMR spectrometer equipped with a $5 \mathrm{~mm} z$-axis gradient AutoX probe operating at the nominal ${ }^{1} \mathrm{H}$ frequency of $400 \mathrm{MHz}$ and ${ }^{13} \mathrm{C}$ frequency of 100 MHz. All spectra are reported in parts per million (ppm) relative to the residual solvent peak in ${ }^{1} \mathrm{H}$ NMR and the deuterated solvent peak in ${ }^{13} \mathrm{C}$ NMR. Mass samples were analyzed on a hybrid linear ion trap (LIT) Fourier transform-ion cyclotron resonance mass spectrometer (LTQ-FT, Thermo Electron, Bremen, Germany) equipped with a TriVersa NanoMate ion source (Advion BioSciences, Ithaca, NY) with an electrospray chip (nozzle inner diameter $5.5 \mathrm{~lm}$ ). The TriVersa NanoMate was operated in positive ion mode by applying $1.85 \mathrm{kV}$ with $0.1 \mathrm{psi}$ head pressure. Melting points were acquired using Fisher-Johns melting point apparatus.

\section{Synthesis of alkoxyurea thiol 1}

$N$-Alkoxyphthalimide 2 (Scheme 1) was prepared according to a literature procedure. ${ }^{39}$ 1-(tert-Butyl)-3-((11-mercapto-undecyl) oxy)urea (3) was prepared by analogy to a reported method. ${ }^{40}$ The progress of reactions was monitored by thin-layer chromatography using silica gel $60 \AA$ F-254 plates. The plates were visualized first by UV illumination and then by staining using a $p$-anisaldehyde stain. Column chromatography was performed using silica gel (230-400 mesh).

2-(Undec-10-en-1-yloxy)isoindoline-1,3-dione (2). To a solution of $N$-hydroxyphthalimide (NHP) $(5.56 \mathrm{~g}, 34.1 \mathrm{mmol})$ and sodium bicarbonate $(2.76 \mathrm{~g}, 32.9 \mathrm{mmol})$ in DMF $(60 \mathrm{~mL})$ at $80{ }^{\circ} \mathrm{C}$ was added 11-bromo-1-undecene $(2.83 \mathrm{~mL}, 12.9 \mathrm{mmol})$. After stirring $10 \mathrm{~h}$, the reaction mixture was allowed to cool to room temperature and then poured into water $(60 \mathrm{~mL})$. The aqueous layer was extracted with ethyl acetate $(4 \times 60 \mathrm{~mL})$. The combined organic layer was washed with $5 \% \mathrm{LiCl}$ solution $(2 \times$
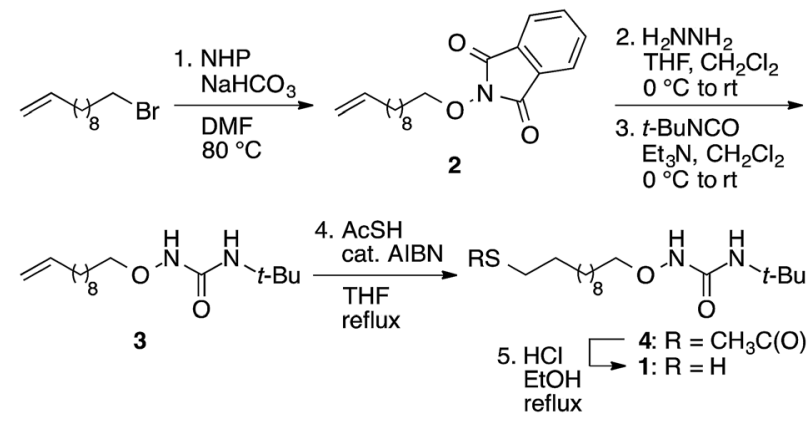

Scheme 1 Synthesis of urea thiol 1; NHP $=N$-hydroxyphthalimide, AIBN $=$ azobis(isobutyronitrile).
$50 \mathrm{~mL})$, dried $\left(\mathrm{MgSO}_{4}\right)$, filtered, and then concentrated by rotary evaporation. The crude product was purified by $\mathrm{SiO}_{2}$ column chromatography, eluting with a 15:85 mixture of EtOAc : hexane, to afford $3.51 \mathrm{~g}(86 \%)$ of 2 as a white solid; $\mathrm{mp}$ $=35-37{ }^{\circ} \mathrm{C}$ (lit. $\left.41 \mathrm{mp}=38-40{ }^{\circ} \mathrm{C}\right)$; TLC, $R_{\mathrm{f}}=0.69(2.5: 7.5$, EtOAc : hexane); ${ }^{1} \mathrm{H}$ NMR $\left(\mathrm{CDCl}_{3}, 400 \mathrm{MHz}\right) \delta 7.84-7.82(\mathrm{~m}, 2 \mathrm{H})$, 7.75-7.73 (m, 2H), 5.81-5.79 (m, 1H), 5.00-4.90 (m, 2H), $4.19(\mathrm{t}, J$ $=5.6 \mathrm{~Hz}, 2 \mathrm{H}), 2.04-2.00(\mathrm{~m}, 2 \mathrm{H}), 1.80-1.76(\mathrm{~m}, 2 \mathrm{H}), 1.49-1.47$ (m, 2H), 1.36-1.29 (m, 10H) ppm; ${ }^{13} \mathrm{C} \mathrm{NMR}\left(\mathrm{CDCl}_{3}, 100 \mathrm{MHz}\right)$ $\delta$ 163.7, 139.2, 134.5, 129.1, 123.5, 114.2, 78.7, 33.9, 29.5, 29.4, 29.3, 29.2, 29.0, 28.2, 25.6 ppm; IR 2923, 2851, 1787, 1730, 1464, $1399,1186 \mathrm{~cm}^{-1}$.

1-(tert-Butyl)-3-(undec-10-en-1-yloxy)urea (3). To a solution of phthalimide $2(1.00 \mathrm{~g}, 3.17 \mathrm{mmol})$ in $\mathrm{CH}_{2} \mathrm{Cl}_{2}(10 \mathrm{~mL})$ at $0{ }^{\circ} \mathrm{C}$ was added hydrazine $(10.2 \mathrm{~mL}$ of $1.0 \mathrm{M}$ solution in THF, 10.2 mmol). The reaction mixture was stirred at $0{ }^{\circ} \mathrm{C}$ for $1.5 \mathrm{~h}$ and then filtered. The retentate was washed with $\mathrm{CH}_{2} \mathrm{Cl}_{2}(10 \mathrm{~mL})$ and the combined organic solvents then were concentrated by rotary evaporation. The crude aminooxy product so obtained was used directly in the next step without further purification (note: protect from carbonyl vapors, such as laboratory acetone).

To a stirred solution of the crude aminooxy intermediate $(0.58 \mathrm{~g}, 3.17 \mathrm{mmol})$ in dry $\mathrm{CH}_{2} \mathrm{Cl}_{2}(15 \mathrm{~mL})$ at room temperature under argon was added dry $\mathrm{Et}_{3} \mathrm{~N}(0.48 \mathrm{~mL}, 3.45 \mathrm{mmol})$ via syringe. The reaction mixture was cooled to $0{ }^{\circ} \mathrm{C}$ and then $t$ butyl isocyanate $(0.32 \mathrm{~mL}, 2.87 \mathrm{mmol})$ was added dropwise over $5 \mathrm{~min}$. The reaction mixture was slowly allowed to reach room temperature and stirred $10 \mathrm{~h}$ before concentrating by rotary evaporation. The residue was purified by $\mathrm{SiO}_{2}$ flash column chromatography, eluting with a $1: 4$ mixture of EtOAc : hexane, to afford $0.62 \mathrm{~g}(68 \%)$ urea 3 as a colorless liquid; TLC, $R_{\mathrm{f}}=0.51$ (2.5 : 7.5, EtOAc : hexane); ${ }^{1} \mathrm{H}$ NMR $\left(\mathrm{CDCl}_{3}, 400 \mathrm{MHz}\right) \delta 6.85$ (br, $\mathrm{NH}), 5.84-5.74(\mathrm{~m}, 1 \mathrm{H}), 5.59(\mathrm{br}, \mathrm{NH}), 5.00-4.90(\mathrm{~m}, 2 \mathrm{H}), 3.77(\mathrm{t}$, $J=6.4 \mathrm{~Hz}, 2 \mathrm{H}), 2.05-2.00(\mathrm{~m}, 2 \mathrm{H}), 1.64-1.57(\mathrm{~m}, 2 \mathrm{H}), 1.36-1.27$ $(\mathrm{m}, 21 \mathrm{H}) \mathrm{ppm} ;{ }^{13} \mathrm{C} \mathrm{NMR}\left(\mathrm{CDCl}_{3}, 100 \mathrm{MHz}\right) \delta 159.3,139.1,114.2$, 76.4, 50.4, 33.8, 29.5, 29.4, 29.18, 29.12, 28.9, 28.1, 26.1 ppm; IR 3422, 3194, 2923, 2855, 1674, 1525, $1457 \mathrm{~cm}^{-1}$.

$S$-(11-((3-(tert-Butyl)ureido)oxy)undecyl) ethanethioate (4). A solution of urea $3(0.5 \mathrm{~g}, 1.75 \mathrm{mmol})$ and azobis(isobutyronitrile) $(0.043 \mathrm{~g}, 0.26 \mathrm{mmol})$ in dry THF $(20 \mathrm{~mL})$ was heated to reflux whereupon thioacetic acid $(0.25 \mathrm{~mL}, 3.51 \mathrm{mmol})$ was added via syringe. The reaction mixture was stirred at reflux $8 \mathrm{~h}$ and then concentrated by rotary evaporation. The residue was purified by $\mathrm{SiO}_{2}$ column chromatography, eluting with a $15: 85$ mixture of EtOAc : hexane, to afford $0.48 \mathrm{~g}(75 \%)$ of 4 as a pale yellow liquid; TLC, $R_{\mathrm{f}}=0.42$ (2.5 : 7.5 EtOAc : hexane); ${ }^{1} \mathrm{H}$ NMR $\left(\mathrm{CDCl}_{3}, 400 \mathrm{MHz}\right) \delta 6.91(\mathrm{br}, \mathrm{NH}), 5.59(\mathrm{br}, \mathrm{NH}), 3.76(\mathrm{t}, J=$ $6.8 \mathrm{~Hz}, 2 \mathrm{H}), 2.84(\mathrm{t}, J=6.8 \mathrm{~Hz}, 2 \mathrm{H}), 2.30(\mathrm{~s}, 3 \mathrm{H}), 1.59-1.50(\mathrm{~m}$, $4 \mathrm{H}), 1.35-1.25(\mathrm{~m}, 23 \mathrm{H}), \mathrm{ppm} ;{ }^{13} \mathrm{C} \mathrm{NMR}\left(\mathrm{CDCl}_{3}, 100 \mathrm{MHz}\right)$ $\delta$ 196.1, 159.2, 76.4, 50.5, 30.7, 30.6, 29.5, 29.2, 28.8, 28.2, $26.1 \mathrm{ppm}$; IR 3427, 2925, 2854, 1689, $1673 \mathrm{~cm}^{-1}$; FT-ICR-MS for $\mathrm{C}_{18} \mathrm{H}_{37} \mathrm{~N}_{2} \mathrm{O}_{3} \mathrm{~S}[\mathrm{M}+\mathrm{H}]^{+}$calcd 361.2519, found 361.2500.

1-(tert-Butyl)-3-((11-mercaptoundecyl)oxy)urea (1). To a solution of $4(0.50 \mathrm{~g}, 1.38 \mathrm{mmol})$ in EtOH $(10 \mathrm{~mL})$ was added $12 \mathrm{~N}$ $\mathrm{HCl}(1.1 \mathrm{~mL}, 11.0 \mathrm{mmol})$. The reaction mixture was heated to reflux and stirred. After $4 \mathrm{~h}$, the reaction mixture was cooled and 
then concentrated by rotary evaporation. The residue was dissolved in water $(10 \mathrm{~mL})$. The resultant solution was cooled to $0{ }^{\circ} \mathrm{C}$ and the $\mathrm{pH}$ was adjusted to slightly alkaline using saturated $\mathrm{NaHCO}_{3}$ solution. The aqueous layer then was extracted with $\mathrm{CH}_{2} \mathrm{Cl}_{2}(4 \times 30 \mathrm{~mL})$. The combined organic phase was washed with saturated $\mathrm{NaCl}(2 \times 20 \mathrm{~mL})$, dried $\left(\mathrm{MgSO}_{4}\right)$, filtered and concentrated under reduced pressure to afford urea thiol 1 $(0.38 \mathrm{~g}, 86 \%)$ as a pale yellow liquid that was directly applied to gold nanoparticles; TLC, $R_{\mathrm{f}}=0.44\left(2.5: 7.5\right.$ EtOAc : hexane); ${ }^{1} \mathrm{H}$ $\mathrm{NMR}\left(\mathrm{CDCl}_{3}, 400 \mathrm{MHz}\right) \delta 6.76$ (br s, $\left.1 \mathrm{H}, \mathrm{NH}\right), 5.60$ (br s, $\left.1 \mathrm{H}, \mathrm{NH}\right)$, $3.77(\mathrm{t}, J=6.8 \mathrm{~Hz}, 2 \mathrm{H}), 2.51$ (q, $J=7.4 \mathrm{~Hz}, 2 \mathrm{H}), 1.61-1.55(\mathrm{~m}$, $4 \mathrm{H}), 1.36-1.26$ (m, 23H, $t$-butyl + aliphatic chain) ppm; ${ }^{13} \mathrm{C} \mathrm{NMR}$ $\left(\mathrm{CDCl}_{3}, 100 \mathrm{MHz}\right) \delta 159.2,76.4,50.4,34.0,29.5,29.4,29.2,29.1$, 28.3, 28.2, 26.1, 24.6 ppm; IR 3426, 2924, 2853, 1689, 1672, $1525 \mathrm{~cm}^{-1}$; FT-ICR-MS for $\mathrm{C}_{16} \mathrm{H}_{35} \mathrm{~N}_{2} \mathrm{O}_{2} \mathrm{~S}^{+}[\mathrm{M}+\mathrm{H}]^{+}$calcd 319.2414, found 319.2419.

\section{Synthesis of thiol-functionalized gold nanoparticles (AuNPs)}

AuNPs were synthesized using a two-phase reduction approach as reported by Brust et al. ${ }^{42}$ Two solutions were prepared as follows: (1) $\mathrm{HAuCl}_{4}(0.05 \mathrm{~g})$ was dissolved in deionized water (4 $\mathrm{mL})$; (2) TOAB $(0.08 \mathrm{~g})$ was dissolved in toluene $(20 \mathrm{~mL})$. The aqueous $\mathrm{HAuCl}_{4}$ solution was added to the toluene TOAB solution with vigorous stirring until all the tetrachloroaurate had transferred into the organic layer. An amount of 1-dodecanethiol, 4-methoxy- $\alpha$-toluenethiol (4-MTT), 11-mercaptoundecanoic acid (11-MUA) or the urea thiol 1 (Table 1) to give a thiol : Au $1: 1$ molar ratio was then added to the toluene mixture. An aqueous solution of $\mathrm{NaBH}_{4}$, freshly prepared by dissolving $\mathrm{NaBH}_{4}(0.056$ $\mathrm{g})$ in deionized water $(4 \mathrm{~mL})$, was slowly added with vigorous stirring to the toluene mixture. A rapid color change occurred as the $\mathrm{NaBH}_{4}$ solution was added. After stirring for at least $3 \mathrm{~h}$ at room temperature, the organic phase was separated and the AuNPs were precipitated by dropwise addition of the organic phase into ethanol $(400 \mathrm{~mL})$ with rapid stirring. After settling overnight, the clear supernatant was decanted and the settled AuNPs were filtered and washed with ethanol. The AuNPs then were dispersed in toluene $(10 \mathrm{~mL})$ and precipitated again by dropwise addition into ethanol $(200 \mathrm{~mL})$. After standing overnight, the suspension was centrifuged and the collected particles were washed with ethanol and dried at $40{ }^{\circ} \mathrm{C}$ in an oven to yield AuNPs (ca. $30 \mathrm{mg}$ ) suitable for sensor formation.

\section{Fabrication of interdigitated electrodes and AuNP film deposition}

Interdigitated electrodes (IDEs) were designed using the microelectromechanical systems (MEMS) software L-Edit to fit onto a 4-inch silicon wafer with a thin insulating layer of $1 \mu \mathrm{m}$ of silicon dioxide. The IDEs then were fabricated using the MEMS microfabrication process, beginning with a sacrificial layer of photoresist coated on the silicon substrate. After photoresist was patterned by photolithography, a $10 \mathrm{~nm}$ thick Ti adhesion layer and a Pt metal layer (200 nm thick) were deposited. Finally, the sacrificial layer was removed by dissolving the photoresist in a solvent to finish a lift-off process. In this way, the IDEs and contact pads remained on the wafer.

The thiol-coated AuNPs in toluene (0.2\%) were sonicated at room temperature for $20 \mathrm{~min}$ and then cast onto the IDE area by dropwise addition. The toluene was evaporated at room temperature to leave a flat, roughly circular film of gold nanoparticles. The AuNPs-coated sensors were then stabilized overnight at $40{ }^{\circ} \mathrm{C}$ in a vacuum oven. After drying, the 1dodecanethiol-, 4-MTT-, 11-MUA- and urea thiol 1-modified AuNPs sensors were used without further manipulation.

\section{Sensor measurements}

AuNPs sensors individually functionalized with the thiol panel listed in Table 1 were placed inside a homemade small stainless steel test chamber with a volume of about $500 \mathrm{~mL}$. The chamber was first evacuated and then a pulse of either synthetic air or a VOC sample was introduced from a sample bag attached to the test chamber and the pressure of the chamber reached atmospheric pressure in a few seconds. After a testing time, the chamber was evacuated again. The VOC samples were prepared using Tedlar bags that had been flushed with synthetic air three times. A known amount of analyte, for example, $3 \mu \mathrm{L}$ of acetone, was injected into a Tedlar bag containing $1 \mathrm{~L}$ synthetic air. As the acetone vaporized within the bag, a gaseous concentration of $1000 \mathrm{ppm}$ was achieved. Then, $10 \mathrm{~mL}$ of the above gas sample was collected by an air-tight glass syringe and injected into a new $1 \mathrm{~L}$ Tedlar bag followed by a dilution process using $990 \mathrm{~mL}$ synthetic air, resulting in an acetone concentration of $10 \mathrm{ppm}$. For lower concentrations of analytes, a similar dilution process was carried out again.

Table 1 Thiols used to functionalize AuNPs

Sensor


The resistance of an individual sensor was monitored at a fixed voltage of $5 \mathrm{~V}$ by a Keithley $2400 I-V$ meter and recorded as a function of time using the Labview program. The output voltage was set and a pulse current of the sensor was sent to the sensor every second. The resistance was calculated based on Ohm's law. In a typical experiment, the sensor response was measured over 5 min under vacuum (28 in $\mathrm{Hg}$ below atmospheric pressure), followed by synthetic air or VOC sample exposure for $5 \mathrm{~min}$ at atmospheric pressure, and then again for 5 min under vacuum. The measurements of synthetic air and VOC in air samples were done at atmospheric pressure. The cycles were repeated at least three times to test reproducibility. Each sensor was examined at different concentrations of acetone, ethanol, ethylbenzene and benzene in air. All experiments were performed at room temperature.

\section{Results and discussion}

Fig. 1a shows a micrograph of scanning electron microscopy of the fabricated IDEs at the core of the sensor. All IDEs were designed to fit into a $400 \mu \mathrm{m} \times 400 \mu \mathrm{m}$ area with both the width of the electrodes and spaces between electrodes of $10 \mu \mathrm{m}$. The two contact pads were $3 \times 3 \mathrm{~mm}^{3}$ for convenient connection to an $I-V$ meter. The overall size of the sensor is rather small in comparison to a one-cent coin (Fig. 1b). Table 1 shows the molecular structures of the synthesized urea thiol and three commercial thiols used to modify AuNPs.

To probe the VOC-tracing capability, the urea thiol 1-functionalized AuNPs sensor was exposed to VOCs in air with varying concentrations in the test chamber. Alternating cycles of sample introduction into the chamber and evacuation were performed while the sensor resistance was monitored and recorded as a function of time. The sensor resistance in the presence of added acetone decreased in comparison with that in synthetic air because of the interactions between acetone and urea thiol 1 on the surface of the AuNPs. The sensor response is defined by the following equation for resistance decrease from air to analyte: $:^{2,3}$

$$
\text { Response }=\left(R_{\text {air }}-R_{\text {gas }}\right) / R_{\text {gas }}
$$

where $R_{\text {air }}$ and $R_{\text {gas }}$ are the resistances of the sensor in synthetic air and in the presence of added target analyte in air samples.

Fig. 2 shows the responses of the urea thiol-AuNPs sensor for sensing acetone in air at a concentration range of $10 \mathrm{ppb}$ to $10 \mathrm{ppm}$. As the concentration of acetone increases, the sensor

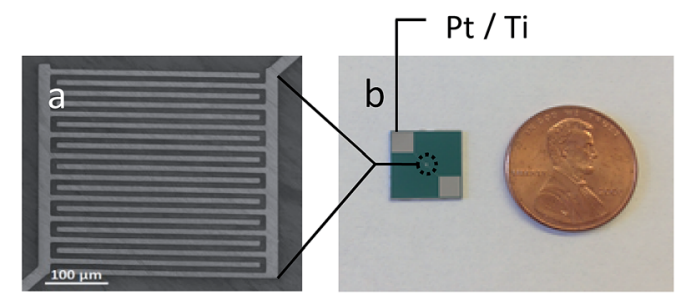

Fig. 1 (a): SEM micrograph of the microfabricated IDE electrodes; (b): size comparison between the sensor and a US one-cent coin.

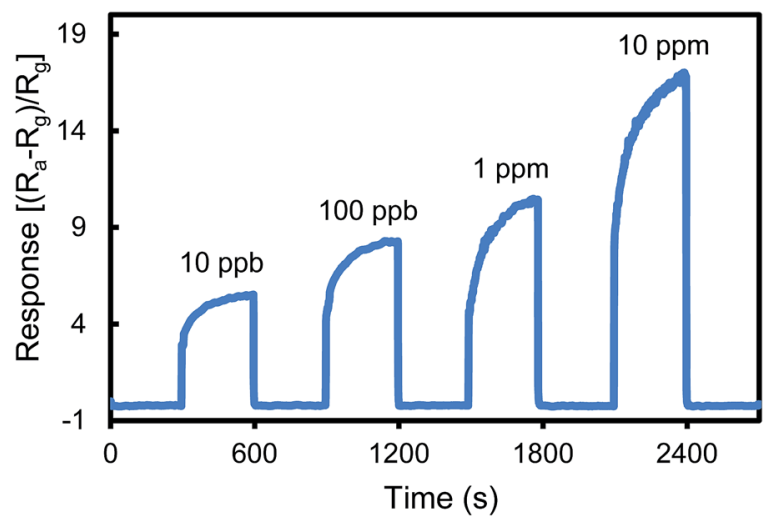

Fig. 2 Response of the urea thiol 1 AuNPs sensor to acetone exposure at $10 \mathrm{ppb}$ to $10 \mathrm{ppm}$.

resistance decreases and thus the response increases. The urea thiol-AuNPs sensor is sensitive toward acetone at a concentration as low as $10 \mathrm{ppb}$, a level of detection more sensitive than most current metal oxide-based acetone sensing devices and thiol functionalized AuNPs sensors..$^{2-12,30-32}$ Furthermore, the response increased with increasing acetone concentration up to 10 ppm, thus demonstrating a wide dynamic range of measurements.

Given this high sensitivity toward acetone, we set out to test the carbonyl-sensing selectivity of the urea thiol-AuNPs sensor by measuring the sensor responses to non-carbonyl VOCs. Fig. 3 shows linear relationships between the sensor response and the common logarithm of the concentrations of acetone, ethanol, benzene, ethylbenzene and water, ranging from $10 \mathrm{ppb}$ to $10 \mathrm{ppm}$. As the slope of the linear regression curve is a direct measure of sensitivity, the relatively flat slopes obtained for the non-carbonyl analytes (all slopes below 1.6) imply that the sensor discriminates in its interactions with VOCs. The considerably stronger response to acetone (slope $=4.6$ )

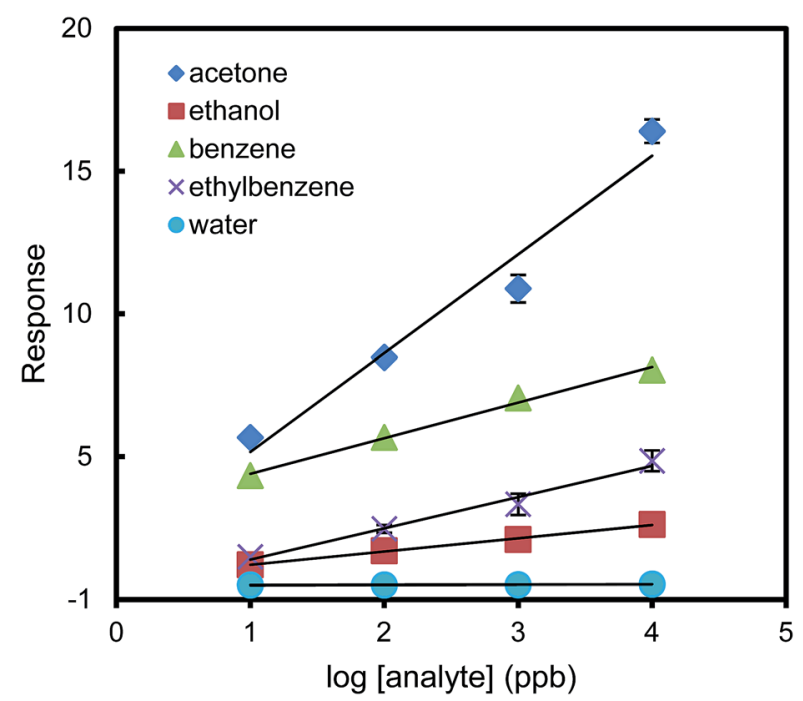

Fig. 3 Sensor response versus log[analyte (ppb)] in detection of acetone, ethanol, benzene, ethylbenzene and water vapor. The responses are nearly linear $\left(R^{2}>0.97\right)$. Error bars indicate the variability among three different sensors. 
suggests the hydrogen bonding design concept for acetone is operative and imparts both sensitivity and selectivity. The sensor is not sensitive to ethanol and water moisture in the tested concentration range, but is relatively sensitive to benzene. The large slope difference between the sensor response curves of acetone and benzene shown in Fig. 3 may provide a way to distinguish these two compounds by a series of simple dilutions of the samples to obtain the slopes of the response curves. For water and ethanol concentration even at a high concentration of $10 \mathrm{ppm}$, the responses of the sensor are smaller than that for sensing $10 \mathrm{ppb}$ acetone. Therefore, the interference of water and ethanol can be negligible up to $10 \mathrm{ppm}$ for sensing acetone in air.

Fig. 4 shows a schematic illustration of a proposed model of the urea thiol molecular self-assembly and interaction with acetone on the surfaces of AuNPs. The urea motifs form hydrogen bonds among adjacent chains on the surfaces of AuNPs as well as hydrogen bonds with incoming acetone. It is reasonable to expect that hydrogen bonding between adjacent ureas is weakened when bulky tert-butyl groups are placed on nitrogen of the urea functionality, ${ }^{43}$ thus accommodating more acetone as its concentration increases.

We surmise that the urea thiol is sensitive to acetone and insensitive to ethanol and water due to the strong molecular interactions of the carbonyl moieties with the urea motifs, whereas ethanol and water may have weaker interactions with the urea motif due to stronger intermolecular interactions with other ethanol or water molecules. The higher responses to benzene and ethyl benzene in comparison with ethanol and water suggest that benzene and ethyl benzene may nest within the hydrophobic chain domains of the urea thiol network in the absence of any significant intermolecular interactions among these analytes.

To further escalate the role of the H-bonding motif of the urea thiol in recognition of carbonyl moieties, the urea thiolAuNPs sensor was compared with AuNPs sensors derived from different thiols, namely 1-dodecanethiol, 4-MTT, and 11MUA shown in Table 1. Fig. 5 shows that the commercial thiolderived AuNPs sensors respond to acetone vapor with considerably lower sensitivities than the urea thiol-AuNPs sensor.

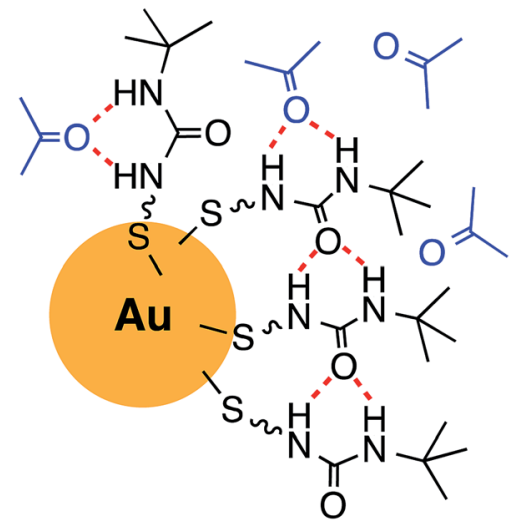

Fig. 4 Schematic illustration of the urea thiol self-assembly on the surface of a AuNP and interaction with acetone.

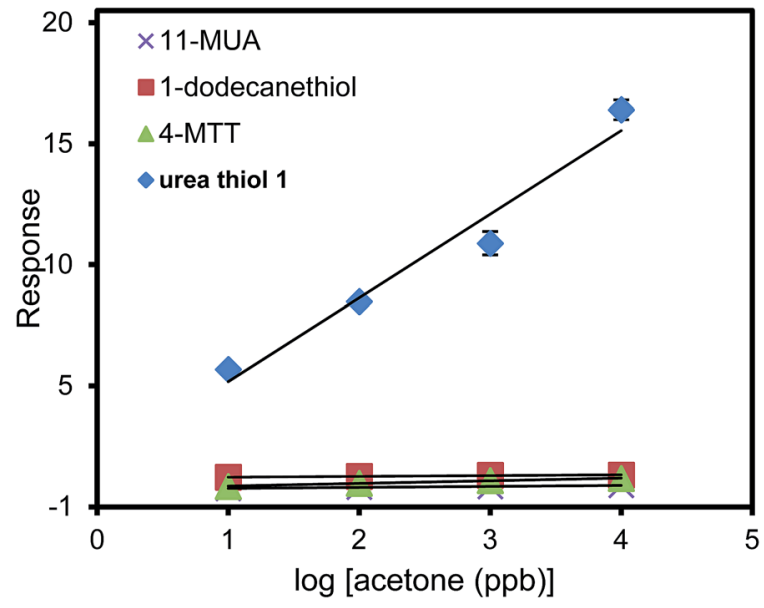

Fig. 5 Responses for sensors derived from AuNPs coated with urea thiol 1, 1-dodecanethiol, 4-methoxy- $\alpha$-toluenethiol (4-MTT) or 11mercaptoundecanoic acid (11-MUA) in detection of acetone.

Indeed, at a general concentration of acetone of $1 \mathrm{ppm}$, the response of the urea thiol AuNPs sensor was $\sim 10,12$ and 23 times higher than the 1-dodecanethiol-, 4-MTT and 11-MUAfunctionalized AuNPs sensors, respectively. These results strongly support that incorporation of terminal functionality on a thiol monolayer surrounding AuNPs can be used to confer sensitivity and selectivity in analyte detection. Along these lines, the sensor derived from 4-MTT responded selectively to ethanol, albeit at a substantially lower response relative to the urea thiolderived sensor in its detection of acetone. ${ }^{38}$ Fig. 6 shows the responses of the sensors derived from AuNPs coated with the four thiols in detection of a mixture of $1 \mathrm{ppb}$ benzene, $1 \mathrm{ppb}$ ethanol and acetone varied from $1 \mathrm{ppb}$ to $100 \mathrm{ppb} .1 \mathrm{ppb}$ of interfering VOCs was chosen because normally the concentrations of these VOCs in environmental air are lower than $1 \mathrm{ppb}$. The urea thiol AuNPs sensor responded with increases in acetone concentration, as shown in Fig. 3. Responses to VOC mixtures were higher than that of only acetone spiked into synthetic air. The contribution of benzene to the sensor response for a mixture of $1 \mathrm{ppb}$ each of benzene, ethanol and

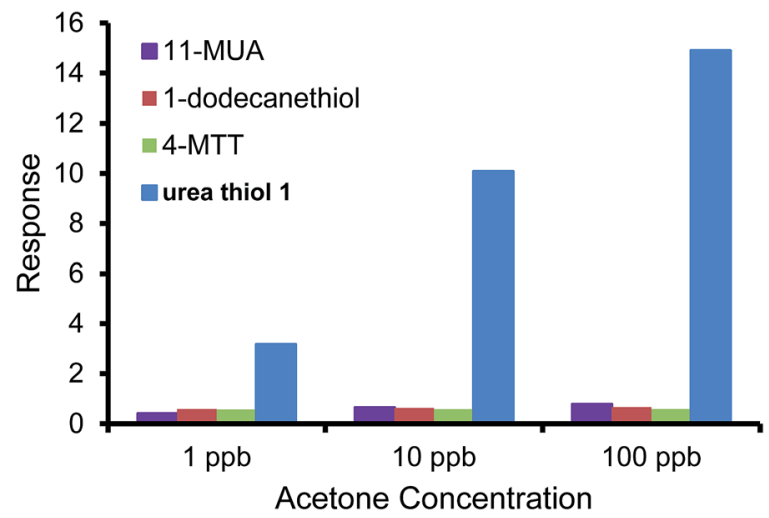

Fig. 6 The responses of sensors derived from AuNPs coated with urea thiol 1, 1-dodecanethiol 4-methoxy- $\alpha$-toluenethiol (4-MTT) and 11mercaptoundecanoic acid (11-MUA) in detection of a mixture of $1 \mathrm{ppb}$ benzene, $1 \mathrm{ppb}$ ethanol and acetone varied from $1 \mathrm{ppb}$ to $100 \mathrm{ppb}$. 
acetone likely is larger than acetone. However, in comparison, the other thiol-derived sensors showed little sensitivity to VOC mixtures with increasing acetone concentrations.

On comparing the acetone sensing performance of the urea thiol 1-derived sensor to other chemiresistors reported in the literature, ${ }^{2-12,23-32}$ we noted differences in several key parameters that underscore the advantages of the present design. First, an operating temperature under ambient conditions is preferable. Second, the present design features high sensitivity with a low limit of detection and a wide dynamic range for acetone detection, as would be needed for the challenging analytical application of breath analysis. This present study provides a paradigm using size complementary thiol-urea $\mathrm{H}$-bond receptor functionalized AuNPs to enhance affinity and selectivity of a chemiresistor for sensing carbonyl vOCs.

\section{Conclusion}

The urea-functionalized thiol AuNPs sensor described herein provided a high sensitivity and good relative selectivity for detection of acetone in reversible and reproducible manner at ambient temperature. Gas sensing measurements reveal that this sensor shows the lowest limit of detection to acetone among the reported chemiresistors to date. The concept of designed thiols for selective interaction with target analytes based on functional group interactions, such as urea-carbonyl hydrogen bonding, may well serve as a powerful strategy to improve chemiresistor sensitivity and selectivity in detection of other VOC classes.

\section{Conflicts of interest}

There are no conflicts to declare.

\section{Acknowledgements}

We gratefully acknowledge financial support by NIH (P42 ES023716).

\section{References}

1 C. Turner, P. Spanel and D. Smith, Physiol. Meas., 2006, 27, 321-337.

2 M. Righettoni, A. Tricoli and S. E. Pratsinis, Anal. Chem., 2010, 82, 3581-3587.

3 L. P. Qin, J. Q. Xu, X. W. Dong, Q. Y. Pan, Z. X. Cheng, Q. Xiang and F. Li, Nanotechnology, 2008, 19, 185705.

4 S. H. Yan, S. Y. Ma, W. Q. Li, X. L. Xu, L. Cheng, H. S. Song and X. Y. Liang, Sens. Actuators, B, 2015, 221, 88-95.

5 B. Bhowmik, V. Manjuladevi, R. K. Gupta and P. Bhattacharyya, IEEE Sens. J., 2016, 16, 3488-3495.

6 V. K. Tomer and S. Duhan, J. Mater. Chem. A, 2016, 4, 10331043.

7 N. H. Al-Hardan, M. J. Abdullah and A. A. Aziz, Appl. Surf. Sci., 2013, 270, 480-485.
8 R. Rella, J. Spadavecchia, M. G. Manera, S. Capone, A. Taurino, M. Martino, A. P. Caricato and T. Tunno, Sens. Actuators, B, 2007, 127, 426-431.

9 L. Geng, Y. Q. Zhao, X. L. Huang, S. R. Wang, S. M. Zhang and S. H. Wu, Sens. Actuators, B, 2007, 120, 568-572.

10 J. S. Park, X. P. Shen and G. X. Wang, Sens. Actuators, B, 2009, 136, 494-498.

11 A. Teleki, S. E. Pratsinis, K. Kalyanasundaram and P. I. Gouma, Sens. Actuators, B, 2006, 119, 683-690.

12 C. Q. Ge, C. S. Xie and S. Z. Cai, Mater. Sci. Eng., B, 2007, 137, 53-58.

13 E. S. Snow, F. K. Perkins and J. A. Robinson, Chem. Soc. Rev., 2006, 35, 790-798.

14 P. Qi, O. Vermesh, M. Grecu, A. Javey, O. Wang, H. J. Dai, S. Peng and K. J. Cho, Nano Lett., 2003, 3, 347-351.

15 N. J. Pinto, I. Ramos, R. Rojas, P. C. Wang and A. T. Johnson, Sens. Actuators, B, 2008, 129, 621-627.

16 C. L. Li, N. Chartuprayoon, W. Bosze, K. Low, K. H. Lee, J. Nam and N. V. Myung, Electroanalysis, 2014, 26, 711-722.

17 S. Vallejos, I. Gracia, J. Bravo, E. Figueras, J. Hubalek and C. Cane, Talanta, 2015, 139, 27-34.

18 L. Han, X. J. Shi, W. Wu, F. L. Kirk, J. Luo, L. Y. Wang, D. Mott, L. Cousineau, S. I. I. Lim, S. Lu and C. J. Zhong, Sens. Actuators, B, 2005, 106, 431-441.

19 H. Ahn, A. Chandekar, B. Kang, C. Sung and J. E. Whitten, Chem. Mater., 2004, 16, 3274-3278.

20 G. Peng, U. Tisch, O. Adams, M. Hakim, N. Shehada, Y. Y. Broza, S. Billan, R. Abdah-Bortnyak, A. Kuten and H. Haick, Nat. Nanotechnol., 2009, 4, 669-673.

21 U. Tisch and H. Haick, Rev. Chem. Eng., 2010, 26, 171-179.

22 E. Chow, K. H. Muller, E. Davies, B. Raguse, L. Wieczorek, J. S. Cooper and L. J. Hubble, J. Phys. Chem. C, 2010, 114, 17529-17534.

23 H. Wohltjen and A. W. Snow, Anal. Chem., 1998, 70, 28562859.

24 H. L. Zhang, S. D. Evans, J. R. Henderson, R. E. Miles and T. H. Shen, Nanotechnology, 2002, 13, 439-444.

25 N. Krasteva, I. Besnard, B. Guse, R. E. Bauer, K. Mullen, A. Yasuda and T. Vossmeyer, Nano Lett., 2002, 2, 551-555.

26 F. J. Ibanez, U. Gowrishetty, M. M. Crain, K. M. Walsh and F. P. Zamborini, Anal. Chem., 2006, 78, 753-761.

27 F. J. Ibanez and F. P. Zamborini, ACS Nano, 2008, 2, 15431552.

28 Y. Joseph, B. Guse, T. Vossmeyer and A. Yasuda, J. Phys. Chem. C, 2008, 112, 12507-12514.

29 F. I. Bohrer, E. Covington, C. Kurdak and E. T. Zellers, Anal. Chem., 2011, 83, 3687-3695.

30 J. K. Kim, Y. S. Yang, S. C. Ha, S. M. Cho, Y. S. Kim, H. Y. Kim, H. Yang and Y. T. Kim, Sens. Actuators, B, 2005, 106, 189-198.

31 S. M. Briglin, T. Gao and N. S. Lewis, Langmuir, 2004, 20, 299-305.

32 F. J. Ibanez and F. P. Zamborini, Small, 2012, 8, 174-202.

33 G. Konavalina and H. Haick, ACS Appl. Mater. Interfaces, 2012, 4, 317-325.

34 G. Konvalina and H. Haick, Acc. Chem. Res., 2014, 47, 66-76.

35 X. Z. Luo, X. J. Jia, J. H. Deng, J. L. Zhong, H. J. Liu, K. J. Wang and D. C. Zhong, J. Am. Chem. Soc., 2013, 135, 11684-11687. 
36 H. Wang, B. Li, H. Wu, T. L. Hu, Z. Yao, W. Zhou, S. Xiang and B. Chen, J. Am. Chem. Soc., 2015, 137, 9963-9970.

37 M. Kaftory, M. Kapon and M. Boroshansky, Chem. Mater., 1994, 6, 1245-1249.

38 Z. Xie, M. V. R Raju, B. B. Brown, A. C. Stewart, M. H. Nantz and X. A. Fu, Transducers, 2017, 1425-1428.

39 S. Park and M. N. Yousaf, Langmuir, 2008, 24, 6201-6207.
40 J. Willwacher, S. Rakshit and F. Glorius, Org. Biomol. Chem., 2011, 9, 4736-4740.

41 N. Dendane, A. Hoang, L. Guillard, E. Defrancq, F. Vinet and P. Dumy, Bioconjugate Chem., 2007, 18, 671-676.

42 M. Brust, M. Walker, D. Bethell, D. J. Schiffrin and R. Whyman, J. Chem. Soc., Chem. Commun., 1994, 7, 801-802.

43 R. Paulini, B. L. Frankamp and V. M. Rotello, Langmuir, 2002, 18, 2368-2373. 